\title{
The Effects of Horticultural Therapy on the Well-Being and Hope of Women in Rural Korea
}

Soon Min, Yun-Ju Ha, Jung-Hwa Kang and Hee-Young Kang

Chosun University, Gwangju, Korea, Republic of Korea.

"Corresponding author: Hee-Young Kang, Chosun University, Gwangju, Korea, Republic of korea, E-mail: moohykang@naver.com

Received date: August 14, 2014; Accepted date: October 29, 2014; Published date: November 1, 2014

Copyright: (c) 2014 Kang HY et al. This is an open-access article distributed under the terms of the Creative Commons Attribution License, which permits unrestricted use, distribution, and reproduction in any medium, provided the original author and source are credited.

\begin{abstract}
Purposes: Horticultural therapy (HT) is an enjoyable and accessible method of recreation that readily lends itself to a variety of healthful lifestyle activities. $\mathrm{HT}$ is valued for its physical, cognitive, social, emotional, and recreational benefits. This study was designed to examine the effects of HT on the psychological well-being and hope of rural women.

Methods: HT consists of three stages: establishing credibility (sessions 1-3), well-being and interpersonal relationships improvement (session 4-22), and maintenance (sessions 23-24). Participants consisted of 45 women from rural Korea, of which 21 were assigned to the experimental group and 24 to the control group. The experimental participants attended 24 sessions of $\mathrm{HT}$.
\end{abstract}

Results: Two groups undergone the program had a significant difference in the psychological well-being and hope.

Conclusions: The findings of this study show that HT has positive effects on psychological and emotional health, and can be utilized as an intervention to help rural women.

Keywords: Horticultural therapy; Rural women; Well-being; Hope

\section{Introduction}

The rural population of Korea is 3.43 million, accounting for $7.3 \%$ of the total population. In 2010, the estimated rural population was 2.96 million, of which 1.51 million (51\%) are female [1].

In spite of the current situation of mechanized agriculture, fewer people working make the farmworks very dependent on rural women. In addition, they increase the hardship of rearing children, supporting parents-in-law due to aging of rural area, doing housework, and fulfilling the role of a wife [2].

Due to these multiple roles, rural women have experienced increasingly more frequent health problems compared to those who live in metropolitan areas [3]. Specifically, rural women have higher incidences of depression, anxiety, low self-esteem, and stress, as well as physical illnesses, such as arthritis and heart disease $[3,4]$. Furthermore, rural women often do not have sufficient time to nurture their children, and they lack confidence in their ability to parent. They have less income and cultural exposure in comparison to their metropolitan counterparts, resulting in a lower quality of life [5].

The quality of life encompasses the concept of well-being and hope. Well-being is defined as how satisfied an individual is with his or her own life [6]. Hope is the belief that one's situation may improve $[7,8]$. People who have a strong sense of well-being and hope are able to cope with stress and engage in relationships, and they typically have the motivation necessary to reach their goals [9]; however, the excessive burdens placed on rural women can negatively affect their psychological health by lowering their quality of life $[4,10]$. In order for rural women to improve their physical, psychological, and social health, it is necessary to implement activities that will positively affect these women's lives.

Recently, from a study investigating several activities for their effects on quality of life and cultural benefits on rural women, horticultural therapy (HT) is emerging due to its use of natural flowers and plants, and engages all of the sensory systems, and it has been used for the treatment of mental illnesses since 1879 [11]. HT is also a popular and accessible method of recreation that readily lends itself to a variety of healthful lifestyle activities [12].

In many Korean studies, the results of HT for teenagers showed that it decreases stress, depression, and anxiety [13], and improves achievement of goals and confidence [14], relieves depression, and improves self-esteem [15]. An overseas study [16] also stressed that viewing plants through windows can be very effective in promoting emotional stability and recovery from illness. In another study, 59 patients with coronary heart disease were treated with HT, which improved mood in these participants [12]. The results of these studies indicated that HT provides psychological benefits to its participants by stimulating interest in plants, improving social confidence, and promoting positive thinking [17-19].

Currently, it is used by the general public, as well as in residential facilities for people with mental illness, elderly patients with dementia, delinquent adolescents, and prisoners [20,21]. The field of use of HT, however, has not been studies of the use of HT for rural Korean women. The aim of this study of HT was to develop a practical system that positively affects the quality of life, such as increasing the wellbeing and hope, of rural Korean women. 
Citation: $\quad$ Min S, Ha YJ, Kang JH, Kang HY (2014) The Effects of Horticultural Therapy on the Well-Being and Hope of Women in Rural Korea. J

\begin{tabular}{|c|c|c|c|c|}
\hline & 6 & Making a rose basket & & $\begin{array}{l}\text { Building relationships, stimulating senses, and } \\
\text { increasing self-presentation }\end{array}$ \\
\hline & 7 & Making a flower bag & & $\begin{array}{l}\text { Stimulating senses and well-being, increasing self- } \\
\text { sufficiency }\end{array}$ \\
\hline & 8 & Water culture (tomato) & & $\begin{array}{l}\text { Mind tranquility, stimulating senses, comforting } \\
\text { stresses, mind tranquility, and increasing social } \\
\text { ability through interpersonal relationships }\end{array}$ \\
\hline & 9 & Barbola & & $\begin{array}{l}\text { Increasing achieving sentiment through expectancy } \\
\text { and interest }\end{array}$ \\
\hline & 10 & Rosemary cottage & & Causing curiosity and psychological well-being \\
\hline & 11 & Plant transportation & & $\begin{array}{l}\text { Positive consideration improvement and } \\
\text { strengthening active action }\end{array}$ \\
\hline & 12 & Making a dish garden & & $\begin{array}{l}\text { Increasing positive thinking through expectancy and } \\
\text { interest, increasing self-esteem through self- } \\
\text { sufficiency, increasing self-representation, and } \\
\text { expectancy for life value }\end{array}$ \\
\hline & 13 & Man doll topiary & & $\begin{array}{l}\text { Planning for future, increasing self-sufficiency and } \\
\text { satisfaction, and increasing positive thinking }\end{array}$ \\
\hline & 14 & Making a fleshy plant garden & & $\begin{array}{l}\text { Stimulating senses, recognizing life value, improving } \\
\text { self-esteem, hope, and psychological well-being } \\
\text { through repetition }\end{array}$ \\
\hline & 15 & Making a cactus garden & & Finding hope through volition and expectancy for life \\
\hline & 16 & Making a circular artificial flower lease & & $\begin{array}{l}\text { Value of life, increasing positive thinking, increasing } \\
\text { self-sufficiency, and decreasing stress }\end{array}$ \\
\hline & 17 & Growing chrysanthemums & & $\begin{array}{l}\text { Forming interpersonal relationships, stimulating } \\
\text { senses, increasing positive emotions, and } \\
\text { psychological well-being }\end{array}$ \\
\hline & 18 & Making a corsage & individual & $\begin{array}{l}\text { Forming interpersonal relationships, psychological } \\
\text { well-being, and self-representation }\end{array}$ \\
\hline & 19 & Group making a frame with dried flowers & group & $\begin{array}{l}\text { Self-representation, increasing social skills through } \\
\text { interpersonal relationships }\end{array}$ \\
\hline & 20 & Cultivating sprouts & & $\begin{array}{l}\text { Forming interpersonal relationships, improving } \\
\text { motivation, and psychological well-being }\end{array}$ \\
\hline & 21 & Making a collection flower arrangement & & $\begin{array}{l}\text { Forming interpersonal relationships, improving self- } \\
\text { representation, and increasing positive emotions }\end{array}$ \\
\hline & 22 & Orchid-planting in volcanic stone & & $\begin{array}{l}\text { Forming interpersonal relationships, psychological } \\
\text { well-being, and hope }\end{array}$ \\
\hline Maintenance & 23 & $\begin{array}{l}\text { Making an invitation letter with a barbola } \\
\text { card(card with decoration of colored } \\
\text { flowers) }\end{array}$ & group & $\begin{array}{l}\text { Increasing positive thinking, self-satisfaction, } \\
\text { psychological well-being, and forming interpersonal } \\
\text { relationships }\end{array}$ \\
\hline & 24 & Drawing a flower picture and displaying it & & $\begin{array}{l}\text { Increasing positive thinking and self-awareness } \\
\text { through establishment and maintenance of } \\
\text { interpersonal relationships }\end{array}$ \\
\hline
\end{tabular}

Table 1: Horticultural Therapy Schedule.

HT consists of the following three stages: (a) establishing credibility (sessions 1-3), (b) well-being and interpersonal relationships improvement (session 4-22), and (c) maintenance (sessions 23-24).

\section{(a) Establishing Credibility through HT (sessions 1-3)}

In the credibility-establishment stage, overall orientation for HT was conducted. To stimulate interest in HT, flower appreciation and an herbal tea was served to participants. The purpose of the HT was to motivate participants about life.

Sensory stimulation, improving social skills via relationships, and promoting emotional stability were the main goals. The purpose of HT is to help participants become attuned to their senses, improve their level of comfort, and relieve stress. 
Page 4 of 6

\section{(b) Improving well-being and relationships through HT (sessions 4-22)}

To improve the participants' sense of well-being, the participants were asked to recall activities from historic rural life. HT provides opportunities to interact with nature, which revitalizes expressive skills and benefits physical and emotional well-being. The purpose of this stage was to help participants feel hopeful for a new life.

\section{(c) Maintenance stage of HT (sessions 23-24)}

In the maintenance stage of HT, participants sent invitation letter with barbola card their friends and family in order to maximize the effect of the program by encouraging themselves with a sense of accomplishment and social relationship.

\section{Procedure}

Before the intervention began, we collected baseline data from the study participants that included general characteristics, a sense of wellbeing, and hope. The intervention group was provided with HT for 12 weeks. Post-test data, which included senses of well-being and hope, were collected after completion of the intervention.

\section{Measures}

Psychological well-being was measured using a self-reported questionnaire, the Psychological Well-being Scale (PWBS), developed by Ryff [22] and modified for use in Korea by Kim, Kim, and Cha [23]. The questionnaire included 46 items scored in a 5- point Likert- type scale. The items included self-acceptance, positive relationships with others, autonomy, environmental mastery, purpose in life, and personal growth dimensions. Higher scores indicated higher levels of well-being. Using Chronbach's a reliability measure, Kim et al. [23] achieved a Cronbach's $a$ of 0.71 . The Cronbach's $\alpha$ achieved in this study was 0.83 .

Hope was measured using a self-reported questionnaire, the Dispositional Hope Scale (DHS), developed by Snyder et al. [24] and translated into Korean (K-DHS) by Kang [25]. Based on personal traits, the K-DHS consists of the following three content areas: 4 items for pathway thinking, 4 items for agency thinking, and 4 items for filter thinking. There were 12 items scored on a 4-point Likert-type scale. Higher scores indicated higher levels of hope. Using Chronbach's a reliability measure, Kang [25] achieved a Cronbach's a of 0.82 . The Cronbach's $\alpha$ achieved in this study was 0.83 .

\section{Data Analysis}

SPSS PC (14.0) for Windows was used for data analysis. Demographic data were analyzed using descriptive statistics. The Chisquare test and Fisher's exact test were used to determine homogeneity of general characteristics of the experimental group in comparison to the control group. An independent t-test was used to compare differences between the groups' pre-test and post-test outcomes.

\section{Ethical Considerations}

Ethical approval was obtained from the institutional review board of the affiliated institution (IRB-1-015). The participants were assigned to either the experimental group or the control group based on their preferences. All study participants were given both verbal information of the study, where a voluntary participation, guarantee of anonymity, free will of withdrawal from the participation, and no disadvantage upon withdrawal were explained. Upon both verbal and written consents from the women, data was collected.

\section{Results}

\section{General characteristics of the participants}

The characteristics of the experimental and control groups are shown in Tables 2 and 3. Two groups at pre-test had no significant differences in general characteristics, well-being and hope.

\begin{tabular}{|c|c|c|c|c|c|}
\hline \multirow[t]{2}{*}{ Categories } & & Exp. $(n=21)$ & $\begin{array}{l}\text { Cont. } \\
(n=24)\end{array}$ & \multirow[t]{2}{*}{$x^{2}$} & \multirow[t]{2}{*}{$\mathbf{p}$} \\
\hline & & $\mathrm{n}(\%)$ & $\mathrm{n}(\%)$ & & \\
\hline Age (yr) & $\begin{array}{l}39-45 \\
46-55\end{array}$ & $\begin{array}{l}3(14.3) \\
18(85.7)\end{array}$ & $\begin{array}{l}2(8.3) \\
22(91.7)\end{array}$ & $\begin{array}{l}0.40 \\
2\end{array}$ & .652 \\
\hline Religion & $\begin{array}{l}\text { Yes } \\
\text { None }\end{array}$ & $\begin{array}{l}15(71.4) \\
6(28.6)\end{array}$ & $\begin{array}{l}10(41.7) \\
14(58.3)\end{array}$ & $\begin{array}{l}4.01 \\
8\end{array}$ & .071 \\
\hline Education level & $\begin{array}{l}\text { Middle school } \\
\text { High school }\end{array}$ & $\begin{array}{l}9(42.9) \\
12(57.1)\end{array}$ & $\begin{array}{l}8(33.3) \\
16(66.7)\end{array}$ & $\begin{array}{l}0.43 \\
2\end{array}$ & .552 \\
\hline $\begin{array}{l}\text { Monthly income } \\
\text { (US \$) }\end{array}$ & $\begin{array}{l}<1000 \\
1000-2000 \\
2000\end{array}$ & $\begin{array}{l}7(33.3) \\
11(52.4) \\
3(14.3)\end{array}$ & $\begin{array}{l}6(25.0) \\
12(50.0) \\
6(25.0)\end{array}$ & $\begin{array}{l}0.92 \\
5\end{array}$ & .675 \\
\hline Marital state & $\begin{array}{l}\text { Married } \\
\text { Others }\end{array}$ & $\begin{array}{l}20(95.2) \\
1(4.8)\end{array}$ & $\begin{array}{l}21(87.5) \\
3(12.5)\end{array}$ & $\begin{array}{l}0.82 \\
8\end{array}$ & .611 \\
\hline Occupation & $\begin{array}{l}\text { Yes } \\
\text { None }\end{array}$ & $\begin{array}{l}8(38.1) \\
13(61.9)\end{array}$ & $\begin{array}{l}8(33.3) \\
16(66.7)\end{array}$ & $\begin{array}{l}0.11 \\
1\end{array}$ & .765 \\
\hline
\end{tabular}

Table 2: Homogeneity Test for General Characteristics of Participants $(\mathrm{N}=45)$.

\begin{tabular}{|l|l|l|l|l|}
\hline \multirow{2}{*}{ Variables } & Exp.(n=21) & Cont. (n=24) & \multirow{2}{*}{$\mathbf{p}$} & \multirow{2}{*}{} \\
\cline { 2 - 3 } & Mean \pm SD & Mean \pm SD & & \\
\hline Psychological well-being & $3.07 \pm 0.71$ & $2.98 \pm 0.20$ & 0.56 & .576 \\
\hline Hope & $3.45 \pm 0.34$ & $3.40 \pm 0.32$ & 0.46 & .645 \\
\hline
\end{tabular}

Table 3: Homogeneity Test for Outcome Variables at Baseline(N=45).

$$
\text { Exp.=Experimental group; Cont.=Control group }
$$

\section{Psychological Well-being}

The psychological well-being score in the experimental group increased from 3.07 to 3.56 after treatment. The score for the control group was equal from 2.98 to 2.98 . After implementation of HT, the experimental group's psychological well-being was significantly higher than the control group's $(\mathrm{t}=-2.01, \mathrm{p}=.049)$, as shown in Table 4 .

\begin{tabular}{|l|l|l|l|l|l|}
\hline Variables & Pre-test & Post-test & Difference & $\mathbf{t}$ & $\mathbf{p}$ \\
\cline { 2 - 4 } & $\mathrm{M} \pm \mathrm{SD}$ & $\mathrm{M} \pm \mathrm{SD}$ & $\mathrm{M} \pm \mathrm{SD}$ & & \\
\hline \multicolumn{2}{|l}{ Psychological well-being }
\end{tabular}




\begin{tabular}{|c|c|c|c|c|c|c|}
\hline Exp. $(n=21)$ & $\begin{array}{l}3.07 \\
0.71\end{array}$ & & $3.56 \pm 0.61$ & $-0.52 \pm 1.27$ & \multirow[t]{2}{*}{-2.01} & \multirow[t]{2}{*}{.049} \\
\hline Cont...(n=24) & $\begin{array}{l}2.98 \\
0.20\end{array}$ & \pm & $2.98 \pm 0.20$ & $0.00 \pm 0.10$ & & \\
\hline \multicolumn{7}{|l|}{ Hope } \\
\hline Exp.(n=21) & $\begin{array}{l}3.45 \\
0.34\end{array}$ & \pm & $3.61 \pm 0.33$ & $-0.16 \pm 0.33$ & \multirow[t]{2}{*}{-2.18} & \multirow[t]{2}{*}{.042} \\
\hline Cont...(n=24) & $\begin{array}{l}3.40 \\
0.32\end{array}$ & \pm & $3.39 \pm 0.34$ & $0.01 \pm 0.18$ & & \\
\hline
\end{tabular}

Table 4: Changes of Outcome Variables between the Experimental and Control Group (N=45).

\section{Hope}

The hope score in the experimental group increased from 3.45 to 3.61 after treatment. The score for the control group decreased from 3.40 to 3.39. After implementation of HT, the experimental group's hope was significantly higher than the control group's $(\mathrm{t}=-2.18, \mathrm{p}=$. 042), as shown in Table 4.

\section{Discussion}

Compared to women who live in metropolitan areas, rural women have an isolated lifestyle and comparatively more stress. This study investigated the effect of HT on well-being and hope in rural women, wherein it found that HT was very effective in improving well-being and hope in rural women.

HT is defined by the American Horticultural Therapy Association [26] as "a process utilizing plants and horticultural activities to improve the social, educational, psychological, and physical adjustment of persons, thus improving their body, mind, and spirits. HT uses gardening, plants, floral materials, and vegetation to stimulate clients' interest in their surroundings and to promote the development of leisure or vocational skills" [27]. In a meta-analysis of HT [28] in Korea, HT was determined to be a meaningful program since it is within the range of an effective size of 0.93 , based on the standard established by Cohen [29]. In addition, the effective size of the independent variable was significant in regard to the outcomes of improved self-esteem, anxiety, and depression. Moreover, our study investigated psychological variables, such as well-being and hope, which had not been previously investigated. It has been reported that HT has a greater impact on adults, wherein groups of 4-6 or 11-20 for 21-25 sessions optimally maximize benefits to well-being and hope $[28,30]$. Our study was performed with a 21 -subject group, and the experiments were conducted over 24 sessions.

The results of this study found that well-being, the first endpoint of the study, was significantly increased in the HT group. This result was consistent with a previous study conducted by $\mathrm{Ha}$ [11], which reported that HT improves well-being by reducing physical and psychological stresses on elderly women. Söderback et al. [19] reported that, as a result of providing HT to 46 patients with brain damage, emotional, cognitive, and/or sensory motor functions were improved and socialization, health, well-being, and life satisfaction were increased.

Psychological well-being encompasses self-acceptance, positive relationships, autonomy, and control over one's environment, life purpose, and personal development. Results of the present study agree with the results of Lee, Hwang, Song, and Son's study [31], which reported that HT was effective to improve life purpose, self-identity and self-esteem for in middle-aged women.

In this study, the hope of the experimental group increased significantly. Most studies have focused on the use of HT in cancer patients [8,32] (Shin and Park, 2007; Sock and Jung, 2006). Since our study focused on rural women with hope as an endpoint and a comparable study does not exist, it is impossible to compare results; however, hope, social support, and quality of life have meaningful relations $[8,33]$. HT provides a great opportunity to improve hope and self-esteem by presenting achievements to family members at the end of the program.

In the view of nursing research, this research is meaningful in that it provides basic data derived from systemically executed positive intervention via the setting up study templates in psychological intervention. In the view of nursing practice, HT was proven to improve rural women's well-being and hope, such that it can be applied as a nursing intervention. In the view of nursing education, in practice, students can be directed to settle health problems with HT as a nursing process, and such a program can be contained within the curriculum.

\section{Limitation of the study}

Participants were recruited from an agricultural development institute located in B district, J province, Korea. It is unlikely that this population represents all women in the rural areas of Korea which limits the generalization of the results. This study should be repeated on a larger scale with a randomly-selected sample of women from different populations in order to develop a protocol appropriate for nursing intervention. For rural women who have limited cultural exposure, HT is an enjoyable and accessible method of recreation; therefore, more systematic, longitudinal research into this promising therapeutic intervention is justified and necessary.

\section{Conclusions}

The extraordinary workload of rural women often has a negative effect on their psychological health, causing a lack of sense of wellbeing and hope. HT has beneficial psychological effects, like stimulating interest in nature, improving social confidence, and promoting positive thinking. This study found that HT enhances wellbeing and hope in rural women. Through relationships developed during HT among participants and between participants and the researchers, interpersonal relationships, positive sentiments, and selfexpression improved. These findings suggest that HT can be very beneficial to improving the quality of life of women in a rural community setting.

\section{References}

1. Statistics Research Institute (2008) Analysis report on agriculture, forestry and fishery using the 2005 census data.

2. Lee EH, Choi JH (2004) A study on the mental health of middle aged woman living in rural community. J Welf for the Aged 23:231-251.

3. Park JH, Eun Y, Back KS, Lee SS, Shin SC (2007) Determinants of factors influencing health-promotion behaviors of middle-aged rural women. Korean Public Health Research, 33:175-187.

4. Shin KR, Yang JH (2003) Influencing factors on quality of life of middleaged women living in rural area. J Korean AcadNurs 33:999-1007 
Citation: $\quad$ Min S, Ha YJ, Kang JH, Kang HY (2014) The Effects of Horticultural Therapy on the Well-Being and Hope of Women in Rural Korea. J

Page 6 of 6

5. Choi C H, Kim J H (2008) The relationship between leisure satisfaction and mental health of middle aged women living in rural communities. J Sport and Leisure Studies 34:607-16.

6. Kim HY, Kim MS (2000) Analyses on the structure of psychological wellbeing $(\mathrm{PWB})$ and relationship between PWB and subjective well-being (SWB) among Korean married women. Korean J Psychol: Woman 5:27-41.

7. Herth KA (2001) Development and implementation of a hope intervention program. OncolNurs Forum 28:1510.

8. Shin AM, Park JS (2007) The effects of hope intervention on hope and depression of cancer patients staying at home. J Korean AcadNurs 37:994-1002.

9. Snyde CR, Sheavens J, Sympson SC (1997) Hope: An individual motive for social commerce, Group Dynamics: Theory, Res Pract 1:107-118.

10. Hemard JB, Monroe PA, Atkinson ES, Blalock LB (1998) Rural women's satisfaction and stress as family health care gatekeepers. Women Health 28:55-77.

11. Ha SY (2008) The effects of horticulture welfare program on well-being in the female elderly. Chosun University, Master thesis, Gwangju.

12. Mattew W, Jonathan W, Francois H, Ana M, Mariano JR (2005) Effect of horticultural therapy on mood and heart rate in patients participating in an inpatient cardiopulmonary rehabilitation program. J CardiopulmRehabil 25:270-274.

13. Kim RB, Kim HY (2009) Effect of horticultural therapy on stress and stress coping strategy of juvenile delinquents. J Korean Soc People Plants Envir 12:17-23.

14. Kweon YH (2006) Effect of horticultural therapy on the changes of mentality, sociality of mental disorder persons. Seoul National University, Master thesis, Seoul.

15. Jung HJ (2002) Effect of horticultural therapy on the changes of selfesteem and anxiety of the mentally retarded students in high school. KonKuk University, Master thesis, Seoul.

16. Ulrich R S (1984) View though their window may influence recovery from surgery. Science 224:420-421.

17. Mackenzie ER, Agard B, Portella C, Mahangar DJ, Barol J, et al. (2000) Horticultural therapy in long-term care settings. J Am Med DirAssoc 1:69-73.

18. Page $M(2008)$ Gardening as a therapeutic intervention in mental health. Nurs Times104:28-30

19. Söderback I S, Söderström M, Schälander E (2004) Horticultural therapy: the 'healing garden' and gardening in rehabilitation measures at
Danderyd Hospital Rehabilitation Clinic, Sweden. PediatrRehabi 7: 245-60.

20. Kim JH, Jo MK, Park HS, Joo SH, Son GC (2008) Effects of horticultural therapy based on social skill on the improvement of interpersonal relationship and sociality of women with mental retardation. Korean J HortSciTechnol 25:81-89.

21. Sim YE, Seo JK, Lee SH (2008) Effect of horticultural therapy program for improvement of work adjustment skill in people with mental retardation. J VocatRehabil 18:89-115.

22. Ryff CD (1989) Happiness is everything, or is it? Explorations on the meaning of psychological well-being. J PersSocPsychol 57:1069-1081.

23. Kim MS, Kim HW, Cha KH (2001) Analyses on the construct of psychological well-being (PWB) of Korean male and female adults. Kor J SocPersPsychol 15:19-39.

24. Snyder CR, Harris C, Anderson JR, Holleran SA, Irving LM, et al. (1991) The will and the ways: development and validation of an individual differences measure of hope. J PersSocPsychol 60:570-585.

25. Kang LY (2002) Development and application of counseling process hope scales. Sunkyunkwan University, Master thesis, Seoul.

26. American Horticultural Therapy Association (2010) The history and practice of horticultural therapy.

27. Morgan B (1989) Growing together. (5thedn). Pittsburgh: Pittsburgh Civic Garden Center.

28. Hong SH (2006) A meta-analysis of the effects of horticultural therapy. Hanyang University, Master thesis, Seoul.

29. Cohen, J. 1988. Statistical power analysis for the behavioral sciences. (2ndedn). New Jersey : Lawrence Erlbaum Associates.

30. Heliker D, Chadwick A, O'Connell T (2001) The meaning of gardening and the effects on perceived well being of a gardening project on diverse populations of elders. Activities, Adaptation \& Aging 24:35-56.

31. Lee YA, Hwang HJ, Song JE, Son KC (2007) Effect of horticultural therapy using pressed flower based upon logotherapy on the improvement of the purpose in life and ego identity of middle-aged women. Hort Environ Biotechnol 25:277-290.

32. Sock TY, Jung Y S (2006) Effects of a forgiveness nursing intervention program on hope and quality of life in woman cancer patients. Korean OncolNursSoc 6:111-120.

33. Perrins-Margalis NM, Rugletic J, Schepis NM, Stepannski HR, Walsh MA (2000) The immediate effects of a group-based horticulture experience on the quality of life person with chronic mental illness. OccupTherMent Health 16:15-32. 